\title{
ERRATUM
}

\section{Characterizing Programming Systems Allowing Program Self-reference}

\author{
John Case and Samuel E. Moelius III \\ Department of Computer \& Information Sciences \\ University of Delaware \\ 103 Smith Hall \\ Newark, DE 19716 \\ \{case, moelius\} @cis.udel.edu
}

S.B. Cooper, B. Löwe, and A. Sorbi (Eds.): CiE 2007, LNCS 4497, pp. 125-134, 2007.

(C) Springer-Verlag Berlin Heidelberg 2007

DOI 10.1007/978-3-540-73001-9_87

In the online version of the original chapter, the second author's name is incorrect in the metadata. The correct name is Samuel E. Moelius III. 